\title{
02
}

\section{5 años de ciencia del patrimonio cultural}

\section{Emilio Cano}

CENIM, Centro Nacional de Investigaciones Metalúrgicas (CSIC)
Hace 25 años comenzó su andadura la revista PH. Hace 25 años, comenzaba yo también mi andadura en el mundo de la conservación y restauración del patrimonio cultural, con mi primera asignatura optativa sobre el tema dentro de la Licenciatura en Bellas Artes en la Universidad Complutense de Madrid, que concluiría con la especialidad en Restauración (así se llamaba entonces) en el año 1996.

En esos momentos, como estudiante, las fuentes de información a las que recurría eran, básicamente, manuales más o menos generalistas. No era especialmente abundante la cantidad de publicaciones de este tipo que había en español, pero si nos íbamos a publicaciones periódicas, con artículos especializados, el panorama era bastante yermo. Las pocas publicaciones que había estaban editadas por instituciones oficiales, y con un carácter más de difusión y promoción institucional que de medio de comunicación entre profesionales. En este contexto aparece, como pionero, el Boletín informativo del Instituto Andaluz del Patrimonio Histórico.

Mi carrera profesional la enfoqué hacia la vertiente científica de la conservación del patrimonio. Cuando comencé mi doctorado en el CSIC recurría de manera habitual a revistas extrajeras: Studies in Conservation, Journal of the American Institute of Conservation, o los boletines y notas editados por el Canadian Conservation Institute. Por desgracia, en nuestro país no había nada parecido, con un carácter de revista científica, constituida fundamentalmente por contribuciones externas con contenidos de investigación originales y con revisión por pares. El enfoque del Boletín del IAPH, de la revista Pátina, de la ESCRBC de Madrid o las publicaciones del entonces Instituto del Patrimonio Histórico Español iban en otra línea.

La propia disciplina de la ciencia de la conservación, o de la ciencia del patrimonio de manera más amplia, no estaba consolidada en nuestro país. Cualquiera de los que nos hemos dedicado a ello hemos seguido una trayectoria más o menos tortuosa, saltando entre los mundos de las ciencias experimentales, de las humanidades y del arte de manera más o menos complicada. El "qué hace alguien como tú en un sitio como este" lo he venido oyendo demasiadas veces en demasiados lugares.

25 años después, y aunque queda mucho por andar (sigo oyendo alguna vez que cuestionan mi posición basándose en mi formación original), la situación ha cambiado notablemente. La concepción de los análisis científicos como algo

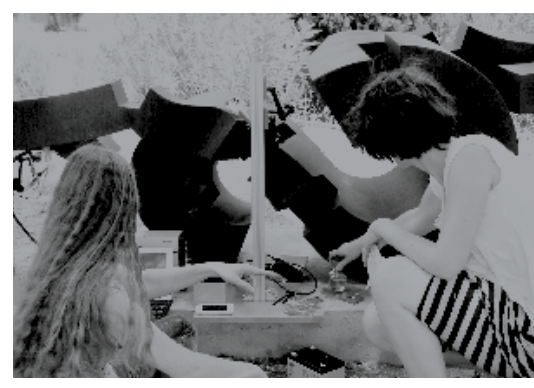

Ensayos electroquímicos sobre la escultura Mediterránea de M. Chirino. Foto Emilio Cano 
rutinario y/o exclusivamente de apoyo a un estudio histórico de un arqueólogo o la intervención de un restaurador está superada, y se entiende que cualquier proyecto de investigación en patrimonio cultural puede ser planteado desde distintos puntos de partida, pero queda cojo si olvida los otros enfoques.

Mi valoración del cambio positivo experimentado en 25 años se basa en la experiencia personal, pero también en un gran número de iniciativas y resultados que han contribuido a construir este cambio, o son reflejo del mismo.

Por empezar por la publicación cuyo aniversario celebramos, la revista $\mathrm{PH}$ se ha consolidado y evolucionado adaptándose a los nuevos tiempos, tanto en aspectos de contenido como formales. En el panorama internacional, la aparición de nuevas revistas, como Journal of Cultural Heritage, International Journal of Conservation Science o, más recientemente, Heritage Science ha permitido dar difusión a una cantidad importante de resultados de investigación en este campo. De alcance más local, pero muy importante para nuestro país, cabe destacar Ge-conservación desde 2009. Aspectos presentes actualmente en estas revistas como la revisión por pares, la publicación en open access, su inclusión en índices reconocidos como los del Web of Science o Scopus (donde, incluso, se ha creado una categoría específica de Conservation), etc., demuestran que este campo ha logrado un nivel de excelencia científica y reconocimiento comparable a otros.

La colaboración entre grupos de investigación de distintas instituciones ha cristalizado en redes como la Red Temática de Patrimonio Histórico y Cultural (RTPHC) del CSIC, iniciada en 2001, y su sucesora desde 2011, la Red de Ciencia y Tecnología para la Conservación del Patrimonio Cultural (TechnoHeritage); en grandes proyectos como el CONSOLIDER-INGENIO Programa de Investigación en Tecnologías para la conservación y revalorización del Patrimonio Cultural (TCP), o los dos programas GEOMATERIALES de la Comunidad de Madrid; en la celebración de congresos como Ciencia y Arte, organizados por el IPCE, o los de la red TechnoHeritage; o en actuaciones como la creación del Observatorio de Investigación en Conservación del Patrimonio Cultural.

\section{"La concepción de los análisis científicos como algo rutinario y/o exclusivamente de apoyo a un estudio histórico de un arqueólogo o la intervención de un restaurador está superada"}

Dentro de las políticas culturales, fue un logro señalado la aprobación del Plan Nacional de Investigación en Conservación (PNIC) en 2011, que supuso una formalización oficial de la importancia de la investigación científica como elemento fundamental para la protección del patrimonio cultural. Es muy destacable también que el Plan Estatal de Investigación Científica y Técnica y de Innovación 2017-2020 recoja de manera específica el alineamiento con los principios del PNIC, tras una serie de planes en los que el patrimonio cultural quedó muy diluido.

En el ámbito europeo, $\mathrm{H} 2 \mathrm{O} 2 \mathrm{O}$ ha financiado un número importante de proyectos en el tema bajo los distintos pilares; se ha reforzado la colaboración entre países bajo la Joint Programming Initiative Cultural Heritage and Global Change (JPI-CH); y el Año Europeo de Patrimonio Cultural 2018 señala la "investigación, innovación, ciencia y tecnología en beneficio del patrimonio" como una de sus iniciativas principales. Por último, la inclusión en la hoja de ruta de infraestructuras de investigación ESFRI de la European Research Infrastructure for Heritage Science (E-RIHS) ha supuesto un hito significativo, con un impacto en la disciplina que veremos en los próximos años, pero que implica reconocer que la ciencia del patrimonio está en la Champions League de la investigación en Europa.

Personalmente, si miro 25 años hacia atrás me siento contento y orgulloso de haber podido aportar mi granito de arena a muchos de estos logros. Estoy seguro de que el futuro de la ciencia del patrimonio es prometedor y me siento ilusionado con los retos, oportunidades y proyectos que nos esperan. 